\title{
O DIREITO À MORADIA E AS POLÍTICAS PÚBLICAS HABITACIONAIS BRASILEIRAS DA SEGUNDA DÉCADA DO SÉCULO XXI
}

\author{
THE RIGHT TO HOUSING AND THE BRAZILIAN HOUSING POLICIES OVER THE SECOND DECADE OF THE 21ST \\ CENTURY
}

\section{RESUMO}

O acelerado processo de urbanização brasileiro provocou intensa demanda de habitação sem que soluções de mercado atendessem as necessidades de moradia urbana. A questão habitacional tornou-se objeto de políticas públicas que historicamente não foram capazes de universalizar o acesso à moradia. $O$ presente artigo tem como objetivo analisar as Políticas Públicas Habitacionais brasileiras da Segunda Década do Século XXI. Analisa-se, portanto, o Programa habitacional Minha Casa Minha vida, a partir de uma concepção do direito à moradia adequada em que a habitação deve vir acompanhada de infraestrutura urbana que garanta dignidade aos seus moradores. Nesse sentido, afirma-se que a referida política não enfrentou o problema do custo da terra e a democratização do seu acesso. Além disso, destaca-se que o seu desenho institucional acabou por monopolizar todo o debate sobre moradia, negligenciando outras formas de produção habitacional.

Palavras-chave: Direito à moradia adequada. Políticas públicas habitacionais.

\section{ABSTRACT}

The accelerating urban sprawl in Brazil isn't meeting the increasing housing demand, and industry solutions have been found lacking. Public Policy has been historically incapable of solving the housing shortage issue. This paper intends to study Brazilian housing policies over the second decade of the 21st century. "My House, My Life" (Minha Casa Minha Vida) program is analyzed with a right to adequate housing in mind, within which housing must be preceded or accompanied by urban infrastructure that offers a basic standard of dignity to its occupants. We conclude that public policy has yet to address the cost of land problem and the democratization of access to it. In addition, its institutional design monopolized the entire debate on housing, neglecting other forms of housing production.

Keywords: The right to adequate housing. Public policy on housing.

\section{Mateus Fernandes Vilela Lima ${ }^{a}$}

${ }^{\text {a }}$ Universidade do Estado do Rio de Janeiro (UERJ), Rio de Janeiro, RJ, Brasil

DOI: $10.12957 /$ geouerj.2020.48406

Correpondência: mateusfvl@gmail.com

Recebido em: 24 set. 2019

Revisado em: 19 nov. 2019

Aceito em: 21 dez.2019 


\section{INTRODUÇÃO}

O presente trabalho aborda o direito à moradia adequada e faz um estudo crítico sobre as políticas públicas arquitetadas para a concreção desse direito. Especificamente, o artigo abordou o Programa Minha Casa Minha Vida, política habitacional hegemônica da Segunda Década do Século XXI formatada para o combate à escassez habitacional brasileira.

Mostrou-se que o favorecimento da propriedade privada ocorreu porque a construção de casas é vista pelo governo como uma maneira de criar empregos, estimular a economia e promover a estabilidade social e política. Neste processo, o Estado tem persuadido milhões de pessoas para se tornarem proprietários. Enquanto a propriedade privada da moradia tem sido encorajada, a moradia digna por outras formas de provimento tem sido negligenciada e até mesmo desacreditada. No entanto, as políticas habitacionais, para serem realmente efetivas, precisam oferecer uma variada gama de alternativas de moradia. Uma mudança nos rumos dessa política torna-se essencial.

Assim, com o intuito de discutir sobre o tema a primeira seção deste artigo discute a moradia como direito. Na sequência, faz-se um arrazoado sobre a positivação desse direito no âmbito nacional, além de trazer algumas classificações necessárias. Em seguida, há análise sobre as relações entre o direito à moradia e a política urbana. O objetivo principal desta parte é sedimentar o conceito do direito à moradia e explicitar seus elementos constitutivos para um melhor desenvolvimento do artigo.

Na segunda seção, são fornecidas bases teóricas úteis ao desenvolvimento do trabalho. Para tanto, pontua-se sobre a política pública habitacional de moradia como política social e política econômica. Em seguida, faz-se um apanhado das políticas habitacionais brasileiras, em especial da Segunda Década do Século XXI. Ao final, são analisados diversos aspectos da política urbana que devem ser executados conjuntamente com a política habitacional para a produção de moradia central e com custo acessível.

Explicado o itinerário, cuida-se agora de percorrer o caminho.

\section{O Direito à Moradia}

Todos nós moramos em algum lugar, ainda que este local seja a rua. A moradia, portanto, é essencial ${ }^{1}$ para a nossa sobrevivência e para se levar uma vida segura, independente e autônoma. Configura-se como

\footnotetext{
1 Segundo Schreiber (2002, p. 81-83), "a não-habitação ou habitação das ruas representa não apenas a perda da moradia, mas a perda da própria condição de pessoa. De fato, todo indivíduo, tende naturalmente a delimitar um espaço de ocupação que lhe possa servir de referência à sua própria identidade. Analisando, por exemplo, o comportamento de pacientes de determinado hospital psiquiátrico do Rio de Janeiro, pesquisadores constatam como práticas frequentes entre os internos o "apego físico a bens pessoas" e a "criação de espaços individuais nos quartos coletivos e nas áreas de convívio comum. [...] Também nas populações de rua verifica-se a tendência a guarda de bens pessoas, à construção de abrigos temporários e à delimitação, senão de um espaço individual, de um território de ocupação dos grupos de convívio habitual.[...] O viver nas ruas - antítese do tema - demonstra, por si
} 
elemento central e condiciona a autoestima, o bem-estar e o acesso das pessoas a equipamentos públicos. Não há qualquer possibilidade de um indivíduo não morar em algum espaço determinado. Ora, ser é ser-nomundo ${ }^{2}$, é ser em um determinado lugar, é morar em algum local. A privação de uma moradia digna repercute como um grave dano ao indivíduo ${ }^{3}$, que persistirá até que se tenha efetivado este direito. Acresça-se que a não efetivação do direito à moradia acarreta danos a diversos outros direitos como o direito ao trabalho, à integridade física, à educação, à saúde, à privacidade, à vida familiar e à participação política (PISARELLO, 2003).

Apesar da extrema importância, a moradia digna não é uma realidade para uma grande parcela dos brasileiros. O déficit habitacional ${ }^{4}$ brasileiro perfaz 6.068 .061 domicílios, desse total, 5.315.251, ou 85,7\%, estão localizados nas áreas urbanas. Acresça-se que "em 2014, são cerca de 11,275 milhões de domicílios carentes de pelo menos um tipo de serviço de infraestrutura, o correspondente a 19,5\% dos domicílios particulares permanentes urbanos do país"(FUNDAÇÃO JOÃO PINHEIRO, 2016, p.58).

Esse grave problema é, em sua maior parte, um problema urbano ${ }^{5}$. O Brasil é hoje um país em que $84,36 \%$ de sua população (160.925.804 habitantes) mora em cidades e 15,64\% habita áreas rurais (29.829.995 habitantes), de acordo com os dados do IBGE relativos ao Censo de 2010. Das nossas regiões, o Sudeste apresenta o maior índice de urbanização, com 90,25\% da população morando em cidades, seguida da região Centro-Oeste, com 88,79\%; região Sul, com 84,93\%; região Norte, com 73,35\%; e região Nordeste com 73,35\% (IBGE, 2012). A predominância da população urbana sobre a rural foi o resultado de uma transformação demográfica dos últimos sessenta anos. Em 1950 a população urbana configurava apenas 36\% da população total brasileira. Este percentual chegou à casa dos 55\% apenas em 1970 , evoluindo para $81 \%$ no ano $2000^{6}$.

\footnotetext{
só a importância da moradia para o desenvolvimento e a manutenção da condição humana. Da mera observação das populações de rua já se conclui que a delimitação de um espaço físico de uso pessoal é pressuposto inafastável da dignidade e da própria personalidade humana".

2 Expressão utilizada por Heidegger que significa dizer que estamos sempre no mundo e existimos sempre em um mundo.

${ }^{3}$ Segundo Carli (2009, p. 11), a moradia "Consubstancia atributo essencial da personalidade, pois é no locus doméstico que as pessoas desenvolvem seu caráter, dão seus primeiros passos rumo ao processo de crescimento espiritual, físico e intelectual. Enfim, é, primeiramente, no espaço do lar, concretizado num teto com paredes, portas, janelas e banheiro, que o indivíduo se sente protegido e seguro para iniciar o aprendizado da vida em relação. Enfim, a capacidade de enfrentar o "mundo da vida" com segurança, autoconfiança e dignidade pressupõe a existência de uma moradia com qualidade".

${ }^{4}$ Como déficit habitacional, entende-se a necessidade de construção de novas moradias para a solução de problemas sociais e específicos de habitação, detectados em certo momento, está ligado, portanto, diretamente às deficiências do estoque de moradias. 5 Por que as cidades atraem tantas pessoas? O poder de atração das cidades é explicado de forma criativa por Raquel Ronik (2004, p.12) quando compara com um imã que atrai as pessoas por questões econômicas, culturais ou religiosas: "[...] na busca de algum sinal que pudesse apontar uma característica da cidade de qualquer tempo e lugar, a imagem que me veio à cabeça foi a de um ímã, um campo magnético que atrai, reúne e concentra os homens".

${ }^{6}$ A título de comparação, segundo dados do relatório World Urbanization Prospects, produzido em 2014 pela Divisão das Nações Unidas para a População do Departamento dos Assuntos Econômicos e Sociais (DESA), a população urbana mundial excedeu a população rural apenas em 2007. O estudo ainda prevê que, em 2050, dois terços da população (66\%) será urbana (ONU, 2014, p.1).
} 
O afluxo imenso de pessoas para as cidades foi acompanhado por uma brutal concentração de renda ${ }^{7}$. Por outro lado, esse processo não foi acompanhado por políticas públicas urbanas e habitacionais que suprissem a demanda crescente por moradia. A consequência urbana desse desenvolvimento é uma cisão da cidade entre quem pode pagar por sua moradia e aqueles que não têm possibilidade para isso. Em função do desemprego e subemprego e da consequente baixa remuneração, parte da população se viu obrigada a reduzir os gastos necessários para sua sobrevivência. Entre esses gastos essenciais estava e está o gasto com a moradia e, como esta camada da população não pode comprar uma propriedade ou alugar, a ocupação ilegal surge como única estratégia de sobrevivência ${ }^{8} 9$. A ilegalidade e a precariedade dessas ocupações repercutem em diversas relações sociais ${ }^{10}$ e reproduz pobreza e violência.

A insatisfação dessas necessidades produz demandas e movimentos sociais que lutam pela implementação e concretização desses direitos. O acesso a terra, e a consequente moradia, sempre foi uma situação complexa no Brasil. Concentrada na mão de poucos, a terra sempre esteve em poder de uma pequena parte da população.

Fundamentalidade, conteúdo, eficácia e aplicabilidade do direito à moradia

A partir dessa realidade, a Emenda Constitucional no 26 consagrou expressamente a moradia como um direito de todo brasileiro em seu artigo 6ㅇ, in verbis: "são direitos sociais a educação, a saúde, a alimentação, o trabalho, a moradia, o transporte, o lazer, a segurança, a previdência social, a proteção à maternidade e à infância, a assistência aos desamparados".

\footnotetext{
${ }^{7}$ Atualmente, apesar de uma relativa melhora nos últimos dez anos, a distribuição de renda brasileira é muito pior do que em diversos países vizinhos. O índice Gini (quanto mais próximo de 1, maior a desigualdade) para o Brasil, em 2013, era de 0,529; enquanto que na Argentina, 0,42; no Uruguai, 0,43; no Paraguai, 0,48; no Chile, 0,50; e no Peru, 0,44 (Dados disponíveis em: $<$ http://datos.bancomundial.org/indicador/SI.POV.GINI>. Acesso em: 03 jul. 2017). Por outro lado, dados do PNAD 2013, indicam que 40 milhões de brasileiros exercem trabalhos informais e não possuem carteira assinada ou qualquer vínculo com a seguridade social, ou seja, $42 \%$ da população ativa não possui carteira de trabalho assinada ou não contribui para a previdência social. Acresçase, ainda, que $45 \%$ dos brasileiros de 16 a 24 anos ocupados exercem trabalhos informais, já entre os idosos este percentual é de $69 \%$ (IBGE, 2015).

${ }^{8}$ Essas ocupações são toleradas pelo Poder Público, conforme Maricato (1999, p. 12): “Como parte das regras do jogo, a ocupação de terras urbanas tem sido tolerada. O Estado não tem exercido, como manda a lei, o poder de polícia. A realidade urbana é prova insofismável disso. Impossível admitir o contrário, pois se essa gigantesca ocupação de terras não fosse tolerada e a população pobre ficasse sem alternativa nenhuma, teríamos uma situação de guerra civil, considerando os números envolvidos. Para dar uma ordem de grandeza, estamos nos referindo a aproximadamente dois milhões de pessoas que moram em favelas, apenas no município de São Paulo".

${ }_{9}^{9}$ Mike Davis (2006, p. 47) chama este processo de "segredo mágico do urbanismo do Terceiro Mundo", um vultuoso subsídio não planejado aos pobres. Ainda, esse mesmo autor chama atenção que esta ocupação pode ser uma estratégia financeira para mercantilização de terras ainda não aproveitadas, nestes termos (p. 97): "os invasores convertem encostas áridas, campos marginais ou alagados pantanosos em terrenos habitáveis, aumentando assim o valor da terra para os proprietários que podem ser despejar os moradores ou aumentar muito o aluguel".

10 Demonstrando essa produção de desigualdade, Rolnik (2002, p. 54) afirm:. "A exclusão é muito mais do que a expressão da desigualdade de renda e das desigualdades sociais: ela é agente de reprodução dessa desigualdade. Em uma cidade dividida entre a porção legal, rica e com infraestrutura e a ilegal, pobre e precária, a população que está em situação desfavorável acaba tendo muito pouco acesso a oportunidades de trabalho, cultura ou lazer. Simetricamente, as oportunidades de crescimento circulam nos meios daqueles que já vivem melhor, pois a sobreposição das diversas dimensões da exclusão incidindo sobre a mesma população fazem com que a permeabilidade entre as duas partes seja muito pequena."
} 
Além de fundamental, a moradia é um direito social. Os direitos sociais são compreendidos como uma materialização "do princípio da dignidade humana na esfera das condições materiais de existência do homem" (BARCELLOS, 2008, p. 197). Visam precipuamente proteger a dignidade da pessoa humana, uma vez que um determinado nível de bem-estar material, social e educacional é condição essencial para assegurar o exercício de liberdades individuais e a participação política do indivíduo na comunidade.

Conforme lição de José Afonso da Silva (2009, p. 286-287), os direitos sociais são prestações positivas estatais enunciadas em normas legais ou constitucionais, que franqueiam melhores condições de vida aos mais fracos, proporcionando a igualização de situações sociais desiguais, se ligam, portanto, ao direito de igualdade ${ }^{11}$. Encontram-se os direitos sociais atrelados à igualdade material e "são, isto sim, um direito das preferências e das desigualdades, ou seja, um direito discriminatório com propósitos compensatórios" (FARIA, 1994, p. 105).

A moradia é uma condição material necessária à dignidade da pessoa humana, trata-se, portanto, de um direito social que proporciona ao indivíduo integração social e desenvolvimento de suas capacidades. A natureza social deste direito é inclusive afirmada pela Constituição da República quando o consagra em seu capítulo II, separando-o dos direitos civis, de nacionalidade e políticos.

A tutela jurídica da moradia tem como foco a pessoa humana e a concretização de sua dignidade. Vêse, portanto, que o direito à moradia tem como principal fundamento a dignidade da pessoa humana ${ }^{12}$. Por estar vinculado à proteção e à promoção da dignidade, o direito à moradia se trata de um direito fundamental $^{13}$. Corroborando com essa afirmação, cita-se a inclusão desse direito no Título II da Constituição de 1988 (Capítulo II, art. 6으), que elenca os “Direitos e Garantias Fundamentais”.

\footnotetext{
11 Veja-se que os direitos sociais também abarcam uma série de direitos de defesa, as liberdades sociais, nas palavras de SARLET (2006, p.57): “Ainda na esfera dos direitos de segunda dimensão, há que atentar para a circunstância de que estes não englobam apenas direitos de cunho positivo, mas também as assim denominadas 'liberdades sociais', do que dão conta exemplos da liberdade de sindicalização, do direito de greve, bem como do reconhecimento de direitos fundamentais aos trabalhadores, tais como direito a férias, e ao repouso semanal remunerado, a garantia de um salário mínimo, a limitação da jornada de trabalho, apenas para citar alguns dos mais representativos. A segunda dimensão dos direitos fundamentais abrange, portanto, bem mais do que os direitos de cunho prestacional, de acordo com o que ainda propugna parte da doutrina, inobstante o cunho 'positivo' possa ser considerado como marco distintivo desta nova fase na evolução dos direitos fundamentais".

12 Conforme as lições de Ingo Sarlet (2009/2010, p. 13-14), a dignidade é o alicerce principal do conceito material dos direitos fundamentais, nestes termos: "Ainda que estejamos convictos de que nem todos os direitos e garantias fundamentais expressamente anunciados no elenco do Título Il de nossa Constituição encontram seu fundamento direto no princípio da dignidade da pessoa humana e que, de qualquer modo, diversa a intensidade deste vínculo entre dignidade e direitos fundamentais, já que distinto o âmbito de proteção de cada direito em espécie, não poderíamos, por outro lado, deixar de reconhecer que é na dignidade da pessoa humana que reside o fundamento primeiro e principal e, de modo particular, o alicerce de um conceito material dos direitos fundamentais".

13 Em posição parcialmente divergente, Ricardo Lobo Torres (2001, p. 289) argumenta que a jusfundamentalidade do direito à moradia se reduz ao mínimo existencial, "E o direito à moradia, é fundamental ou social? No que concerne aos indigentes e às pessoas sem-teto a moradia é direito fundamental, integrando o mínimo existencial e tornando obrigatória a prestação do Estado. Já as moradias populares ou a habitação para a classe média se tornam direitos sociais, dependentes das políticas públicas e das opções orçamentárias".
} 
Conforme Canotilho (2010, p. 378-379), a constitucionalização formal de direitos fundamentais assinala quatro importantes dimensões: (1) colocam as normas em posição hierárquica superior no ordenamento; (2) para modificação destas normas, faz-se necessário um procedimento legislativo diferenciado (art. 60 da CRFB/1988); (3) impõe limites materiais à modificação constitucional (Art. 60, §4o da CRFB/1988); (4) estabelece parâmetros de controle de atuações estatais administrativas, legislativas e jurisdicionais (Art. 5으, $\S 10$ ).

Por outro lado, a fundamentalidade material do direito à moradia "implica a aderência do conteúdo desse direito ao compromisso político comunitário, traçados na Carta Constitucional" (FRANZONI; LUFT, 2014, p. 981). Significa dizer que a moradia, como corolário da dignidade humana, é um fundamento e um objetivo perseguido pelo Estado Brasileiro. Assim, o direito à moradia apresenta fundamentalidade formal (rigidez constitucional, proibição de abolir este direito etc.) e fundamentalidade material ${ }^{14}$ (uma vez que um dos objetivos do Estado brasileiro é a concretização da dignidade da pessoa humana e consequentemente do direito à moradia).

A Constituição não adjetivou o direito à moradia como ocorreu internacionalmente com a adição do adjetivo "adequado"15. No entanto, conforme salientado, a moradia como direito constitucional tem estreita relação com a dignidade humana, constituindo como projeção desta. ${ }^{16}$ Nesse sentido, não há como não ressaltar a adequação que deve qualificar o direito fundamental à moradia para a preservação da dignidade humana. Portanto, não basta apenas ser um teto ou um abrigo, a moradia, como direito fundamental, deve ser adequada com intuito de promover o bem de todos e a redução das desigualdades sociais, fundamento e objetivo do Estado brasileiro, conforme arts. 1으 e 3 ㅇ da Constituição ${ }^{17}$. Não se pode, portanto, pensar a

\footnotetext{
14 Segundo Ingo Sarlet (2006, p.89): “A fundamentalidade material, por sua vez, decorre da circunstância de serem os direitos fundamentais elemento constitutivo da Constituição material, contendo decisões fundamentais sobre a estrutura básica do Estado e da sociedade".

${ }^{15}$ Apenas como curiosidade, a Constituição da Colômbia em seu artigo 51 dispõe sobre o direito à moradia adequado; a de Cuba, em seu artigo 9o, consagra moradia confortável; a do equador em seu artigo 30 utiliza o termo moradia adequada e digna; a mexicana em seu artigo 4ํ utiliza o termo moradia decente e digna; a Constituição da Nicarágua estatui o direito à moradia digna, cômoda e segura (artigo 64); o artigo 100 da Constituição do Paraguai dispõe sobre o direito à moradia digna; a Constituição do Uruguai estabelece em seu artigo 45 o direito a moradia decente, higiênica e econômica; o artigo 82 da Constituição da Venezuela estabelece que toda pessoa tem direito a uma moradia adequada, segura, cômoda, higiênica e com serviços básicos essenciais que incluam um ambiente que humanize as relações familiares, de vizinhança e comunitárias.

${ }^{16}$ No mesmo sentido, advogando a ligação entre moradia e dignidade da pessoa humana Sergio Iglesias Nunes de Souza (2004, p. 43): A moradia consiste em bem irrenunciável da pessoa natural, indissociável de sua vontade e indisponível, que permite a fixação em lugar determinado, não só no físico, como também a fixação dos seus interesses naturais da vida cotidiana, exercendo-se de forma definitiva pelo indivíduo e, secundariamente, recai o seu exercício em qualquer pouso ou local, mas sendo objeto de direito e protegido juridicamente. O bem da "moradia" é inerente à pessoa e independe de objeto físico para a sua existência e proteção jurídica. Para nós "moradia" é elemento essencial do ser humano e um bem extrapatrimonial. "Residência" é o simples local onde se encontraria o individuo. E a "habitação" é o exercício efetivo da "moradia" sobre determinado bem imóvel. Assim, "a moradia" é uma situação de direito reconhecida pelo ordenamento jurídico, assim como ocorreu com o domicílio em relação à residência, na interpretação mencionada por Washington de Barros Monteiro. Dessa forma, moradia também é uma qualificação legal reconhecida como direito inerente a todo o ser humano, notadamente, em face da natureza de direito essencial referente à personalidade humana.

17 Nesse mesmo sentido, cita-se Aina (2009, p. 73): “No Brasil, apesar de o legislador ter optado por incluir no texto da Constituição apenas a expressão "moradia", parece inafastável que a condição de adequabilidade dessa moradia está implícita, pois o sistema
} 
moradia somente relacionada a uma unidade habitacional, mas sim vinculada a seu entorno e ao planejamento urbano. Interessante análise é feita por Gerado Pisarello (2003, p. 84):

\begin{abstract}
La vivienda como unidad, su entorno inmediato y el medio urbano como marco existencial y modo de vida (...) En consecuencia, el grado de dignidad y adecuación de la vivienda no sólo debe predicarse de la unidad-vivienda, sino de su entorno inmediato, y de modo especial del marco urbano o, en su caso, rural de inserción. De todo ello se deriva que el derecho a una vivienda digna y adecuada desemboca, finalmente, en la problemática del urbanismo y de la ordenación del territorio, únicas instancias que hacen posible la efectividad del referido derecho. Así, mientras la vivienda como unidad puede ser entendida como un 'espacio dominado' por los individuos, la vivienda como medio urbano se convierte en 'espacio efectivo' sobre el que los individuos no tienen control pero con el que entran en relación cotidiana, ya que lo utilizan como algo exterior y ajeno para poder desarrollar su propia existencia humana.
\end{abstract}

Com efeito, a implementação do direito à moradia nas áreas urbanas brasileiras, bem como a efetivação do direito à cidade, exige a formulação de políticas públicas de caráter urbanístico, assim "devem se ocupar, para além do direito à moradia, da efetiva integração da participação dos cidadãos nos processos de tomada de decisão, bem como da garantia de acesso aos bens materiais e simbólicos que traduzem a ideia de cidade" (FERNANDES, 2006, p. 19).

Hodiernamente, distingue-se duas dimensões centrais dos direitos fundamentais: a dimensão negativa e a positiva.

A dimensão negativa tem como conteúdo normativo o direito do titular de resistir a intervenções de terceiros em sua esfera de liberdade individual, trata-se de um direito de defesa, um direito de resistência do indivíduo frente a interferências em seus direitos (DIMOULIS; MARTINS, 2014). Impõe-se, aqui, um dever de abstenção, por parte do Estado e dos particulares, de violar posições jurídicas.

A capacidade de produzir efeitos e a consequente aplicabilidade do direito à moradia ${ }^{18}$, em sua função de defesa, não são objetos de questionamentos. Por envolver um dever de abstenção, um comportamento omissivo frente a certas posições jurídicas, não haveria necessidade de prestações fáticas e normativas do Estado. "Em se tratando de direitos de defesa, a lei não se revela absolutamente indispensável à fruição do

jurídico aponta para a valorização da pessoa humana e sua dignidade além de proclamar como fim do Estado a concretização da Justiça social, e estes parâmetros, por certo, implicam habitação salubre e minimamente confortável". No mesmo sentido, Sarlet (2010, p. 17): Não nos parece, especialmente à luz da nossa atual Carta Magna, que um direito à moradia possa, em qualquer hipótese, ser interpretado como um direito a uma moradia não adequada ou, pior ainda, não decente.

18 Neste ponto, cabe um esclarecimento, entende-se por eficácia a capacidade da norma produzir efeitos sem qualquer intermediação legislativa, capacidade de produzir efeitos desde já. Por outro lado, aplicabilidade seria a produção direta dos efeitos em si que teria uma conexão da norma com os fatos. Conforme Virgilio Afonso da Silva (2008, p. 57- 58): “Há aqui, na minha opinião, uma confusão entre a eficácia dos direitos fundamentais, sua forma de produção de efeitos e seu âmbito de aplicação. $O$ texto constitucional, que dispõe que os direitos fundamentais terão aplicação imediata, faz menção a uma potencialidade, à capacidade de produzir efeitos desde já. Mas a simples prescrição constitucional de que as normas definidoras de direitos fundamentais terão 'aplicação imediata' não diz absolutamente nada sobre quais relações jurídicas sofrerão seus efeitos, ou seja, não traz indícios sobre o tipo de relação que deverá ser disciplinada pelos direitos fundamentais. Prescrever que os direitos fundamentais têm 'aplicação imediata' não significa que esta aplicação deverá ocorrer em todos os tipos de relação ou que todos os tipos de relação jurídica sofrerão algum efeito das normas de direitos fundamentais". 
direito" (SARLET, 2009/2010, p. 30), não havendo qualquer razão para não se aplicar o disposto no art. 5ำ, §1ํㅡ, da Constituição Federal, que dispõe que as normas definidoras dos direitos e garantias fundamentais têm aplicação imediata.

Por sua vez, a dimensão positiva do direito à moradia implica postura diversa do Estado, não basta uma omissão, um respeito passivo a um direito. O Estado deve atuar de maneira proativa com intuito de realizar com maior eficácia possível os direitos fundamentais. Essa atuação não significa que o Estado deve construir moradia para toda a população do país e nem mesmo que haveria uma exigibilidade automática de moradia de um indivíduo frente ao poder público. Assim, o direito à moradia exige do Estado a adoção de políticas públicas que evitem a escassez de moradia, os despejos forçados e a discriminação de grupos vulneráveis e excluídos $^{19}$. Essas medidas devem ser tomadas pelos diversos níveis federativos e por todos os Poderes (Legislativo, Executivo e Administrativo).

Não há, portanto, um direito subjetivo a uma determinada prestação material, mas sim um direito a ações estatais que potencializem o acesso à moradia (regulação de uso do solo, implementação dos instrumentos urbanísticos, políticas habitacionais adequadas etc.). Seria um direito de todo cidadão a políticas públicas que concedam de forma efetiva a moradia adequada. A concreção dessas políticas demanda alocação de recursos financeiros e humanos que ficam limitados à questão de disponibilidade de recurso orçamentário 20 .

Assim, a dimensão positiva implica postura proativa do Estado com intuito de realizar com maior eficácia possível os direitos fundamentais. Em sua dimensão objetiva, o direito à moradia se configura como uma

\footnotetext{
${ }^{19}$ Esta também é a visão de Canotilho e Vital Moreira (2007, p. 835) ao comentar o art. 650 da Constituição portuguesa que estabelece o direito a uma habitação adequada a todo cidadão português: "como direito social, o direito à habitação não confere um direito imediato a uma prestação efectiva dos poderes públicos mediante disponibilização de uma habitação; mas, para além das obrigações públicas tendentes a assegurar a oferta de habitações, o direito à habitação garante critérios objetivos e imparciais no acesso dos interessados às habitações oferecidas pelo sector público."

${ }^{20}$ Este diapasão é a mesmo adotado no célebre caso Grootboom julgado pela Corte Constitucional da África do Sul. Transcreve-se em parte aquela decisão: 41 . As medidas adotadas devem estabelecer um programa de moradia coerente e direcionado para a progressiva realização do direito ao acesso à moradia adequada, na medida dos recursos estatais disponíveis. Tal programa deve ser capaz de facilitar a realização do direito. Os contornos precisos e o conteúdo das medidas a serem adotadas são prerrogativas dos Poderes Legislativo e Executivo. Estes devem, contudo, garantir que as medidas adotadas sejam razoáveis. Em qualquer processo judicial fundamentado na Seção 26, e no qual seja alegado que o Estado falhou no atendimento às obrigações positivas impostas pela Seção 26 (2), a questão será se as medidas legislativas e outras ações do Estado são razoáveis. Uma Corte, considerando a razoabilidade, não irá perquirir se outras medidas mais desejáveis e favoráveis poderiam ter sido adotadas, ou se o dinheiro público poderia ter sido mais bem gasto. A questão seria se as medidas adotadas são razoáveis. Necessário admitir que um amplo leque de possíveis medidas pode ser adotado pelo Estado no cumprimento de suas obrigações. Muitas dessas passariam pelo crivo da razoabilidade. Uma vez que restar demonstrado que as medidas são razoáveis, esse requisito terá sido atendido.

42. Demanda-se do Estado a adoção de medidas legislativas e outras ações. As medidas legislativas em si não representam o cumprimento do mandamento constitucional. A mera edição de leis não é suficiente. O Estado é obrigado a agir na direção da obtenção do resultado esperado, e as medidas legislativas terão de ser, invariavelmente, apoiadas por políticas e programas apropriados e bem dirigidos pelo Executivo. Essas políticas e programas devem ser razoáveis, tanto em sua concepção quanto em sua implementação. A formulação de um programa é apenas o primeiro estágio no cumprimento das obrigações estatais. $O$ programa também deve ser razoavelmente implementado. Quer dizer, se um programa é razoável, mas não é razoavelmente implementado, isso não constituirá cumprimento à obrigação estatal. Tradução retirada de Strapazon e Tramontina (2016, p. 307308).
} 
norma programática, um mandado de otimização para a consecução do máximo de eficácia da norma constitucional. O Estado não tem obrigação de construir moradia para toda população, havendo, entretanto, a obrigação de adoção de políticas públicas que evitem a escassez de moradia. Portanto, passa-se a análise, na próxima seção, da natureza da política habitacional.

Política habitacional entre uma política social e a política econômica

A moradia, em uma sociedade capitalista, é entendida como mercadoria disponível para ser vendida e comprada livremente no mercado. $\mathrm{O}$ acesso a este bem, seu uso e utilização são feitos, portanto, por meio de contratos baseados na propriedade privada. Ainda que tais bens estejam disponíveis somente para as pessoas que podem pagar por eles, a moradia e o espaço urbano são substratos essenciais de nossas vidas. Todas as pessoas moram em algum lugar (ainda que de forma precária), circulam em determinado espaço urbano e, portanto, necessariamente, precisam do acesso a esses bens mesmo que não tenham dinheiro para isso (SANTOS JUNIOR, 2011).

Fica evidente que a moradia tem um valor de uso e também um valor de troca. Quando a habitação está sendo usada como residência, quando é meio direto para satisfação de uma necessidade humana de teto, servindo diretamente como um meio de existência, está-se diante do seu valor de uso (quando uso minha casa para minha própria moradia, quando utilizo minha bicicleta para meu transporte diário, quando utilizo minhas roupas para vestimenta etc.). Ao reverso, quando o espaço urbano é tratado como mercadoria, quando se configura como uma proporção de troca entre duas mercadorias, está-se diante do valor de troca (quantos apartamentos de um quarto seriam necessários para trocar por um apartamento de quatro quartos na zona sul do Rio de Janeiro ou quantas bicicletas são necessárias para se trocar por um automóvel) (HARVEY, 1980, p.131).

A cidade é um espaço de luta entre vários personagens, cada qual tentando atingir seu objetivo (valor de troca ou valor de uso). Estrutura-se, portanto, como um lugar, um espaço, uma arena de luta em que se digladiam diferentes agentes sociais com diversas finalidades (SANTOS JUNIOR, 2011).

A análise e a concepção de políticas públicas habitacionais devem ter sempre em mente que a casa, a morada, a habitação além de um bem, configura-se como uma necessidade básica de qualquer pessoa, uma vez que todos nós precisamos de abrigo, privacidade, serviços públicos de infraestrutura etc. Por isso as políticas habitacionais de interesse social devem ser entendidas como instrumental de acesso a um direito fundamental e concebidas para atenuar desigualdades sociais. Portanto, devem ser implementadas como políticas sociais.

Com efeito, ao se analisar o histórico das políticas habitacionais brasileiras, vê-se um predomínio da concepção mercadológica da moradia, uma visão em que o Estado apenas fomentaria o setor imobiliário e 
facilitaria os financiamentos de imóveis, deixando que o mercado regulasse o setor e provesse a moradia às camadas de baixa renda. Assim, imprime-se nas políticas públicas uma racionalidade de mercado, em que o acesso à moradia dar-se-á sempre mediado pela compra da propriedade privada. A moradia é concebida, então, como mercadoria e ativo financeiro e regulada pela lei da oferta e da procura e, consequentemente, a política habitacional é idealizada como política econômica:

No entanto, o poder público vem privilegiando a transferência de propriedade nas políticas habitacionais por uma série de fatores, mas principalmente como forma de estimular a economia e o crescimento do mercado imobiliário. O que acaba por gerar um efeito perverso para os moradores de menor renda, que podem ficar inadimplentes ou serem compelidos a se mudar rapidamente em decorrência do encarecimento dos custos da vida nas áreas objeto dos programas (SANTOS; LUFT; MEDEIROS, 2015, p. 236).

A moradia não é entendida como um direito social a ser provido pelo Estado, mas sim como um produto fornecido pelo mercado. Esse paradigma de política habitacional não tem respondido a contento as necessidades habitacionais das pessoas, em especial aquelas mais pobres.

No Brasil, as políticas habitacionais adotadas têm quase que exclusivamente como escopo a aquisição da casa própria. Apesar do grande volume de recursos financeiros dispensados aos programas habitacionais, bem como o imenso volume produzido de habitação, o déficit habitacional tem aumentado e beira a casa dos 6.068 milhões, segundo dados da Fundação João Pinheiro de 2014. Esse mesmo estudo aduz que o déficit, em 2013, era de 5,846 milhões de unidades.

A política habitacional baseada em acesso à moradia por meio da casa própria, que desconsidera uma demanda diversificada e heterogênea de moradia, não foi capaz, até aqui, de solucionar a questão habitacional. O domínio da casa própria como alternativa a ser buscada e reproduzida nas políticas habitacionais foi construída historicamente e tem como principal fundamento a concepção da política habitacional como uma política econômica. Faz-se necessário, entretanto, na esteira do que foi consagrado nos instrumentos internacionais (UN-HABITAT), bem como nos documentos nacionais (PLANAB - 2009), diversificar essa política. Apesar de não ser a resposta definitiva e única, a locação social representa uma alternativa interessante para minimizar o problema da habitação.

Vistas as linhas gerais das políticas públicas habitacionais, passa-se, na seção seguinte, à análise da Políticas Pública Habitacional Brasileira praticada na Segunda Década do Século XXI, que se resumiu ao Programa Minha Casa Minha Vida (PMCMV).

\subsection{Minha Casa Minha Vida (PMCMV)}

Em 2009, o governo federal lançou o Programa Minha Casa Minha Vida (PMCMV), que tinha por objetivo a construção de moradia para famílias com renda até 10 (dez) salários mínimos. As linhas de ação do PMCMV 
inicialmente podiam ser resumidas a partir da estruturação de três faixas ${ }^{21}$ de renda dos beneficiários da política pública. A partir do ano de 2017, depois de uma mudança de governo por um controverso processo de impeachment, criou-se uma faixa intermediária entre a faixa 1 e 2, chamada de faixa 1,5.

Tabela 1. Fases do Programa Minha Casa Minha vida. Fonte: Autor, 2019. Base de dados: Caixa Econômica Federal (site).

\begin{tabular}{|c|c|c|}
\hline \multicolumn{3}{|c|}{ FASE 1} \\
\hline FAIXAS & SALÁRIOS MÍNIMOS & UNIDADES PREVISTAS \\
\hline 1 & Até 3 (R\$ 1.395 na época) & 400.000 \\
\hline 2 & 3-6 (R\$ 2.790 na época) & 400.000 \\
\hline 3 & $6-10$ ( $R \$ 4.650$ na época) & 200.000 \\
\hline TOTAL DE UNIDADES & & 1.000 .000 \\
\hline \multicolumn{3}{|c|}{ FASE 2} \\
\hline FAIXAS & RENDA & UNIDADES PREVISTAS \\
\hline 1 & Até $\mathrm{R} \$ 1.600,00$ & 1.200 .000 \\
\hline 2 & $R \$ 1.600,00$ a $R \$ 3.100,00$ & 600.000 \\
\hline 3 & $R \$ 3.100,00$ a $R \$ 5.000,00$ & 200.000 \\
\hline TOTAL DE UNIDADES & & 2.000 .000 \\
\hline \multicolumn{3}{|c|}{ FASE 3} \\
\hline FAIXAS & RENDA & UNIDADES PREVISTAS \\
\hline 1 & Até $\mathrm{R} \$ 1.800,00$ & 500.000 \\
\hline 1,5 & $R \$ 1.800,00$ a $R \$ 2.350,00$ & 500.000 \\
\hline 2 & $R \$ 2.350,00$ a $R \$ 3.600,00$ & 800.000 \\
\hline 3 & $R \$ 3.600,00$ a $R \$ 6.500,00$ & 200.000 \\
\hline TOTAL DE UNIDADES & & 2.000 .000 \\
\hline
\end{tabular}

A primeira fase do PMCMV construiu mais de um milhão de unidades habitacionais (600 mil estavam concentradas na faixa de renda 2 e 3). Já a segunda fase teve uma maior preocupação com a demanda habitacional da Faixa 1, a meta de construção foi ampliada para dois milhões de moradias, sendo que 1.200.000 destinadas à Faixa 1. A terceira fase, foi lançada em 2016 e tinha por meta novamente dois milhões de domicílios. Nesta etapa, foi adicionada uma nova faixa de beneficiários a faixa 1,5 e houve um aumento dos limites de renda das outras faixas.

Veja-se que após o afastamento da Presidenta Dilma foi adotado uma política de arrocho e cortes orçamentários, esse panorama influenciou sobremaneira a execução do PMCMV. Em 2017 o governo contratou apenas 23 mil moradias destinadas a famílias de Faixa 1, isso representava apenas 13,5\% da meta

\footnotetext{
${ }^{21}$ A partir do ano de 2016, depois de uma mudança de governo por um processo de impeachment, criou-se uma faixa intermediária entre a faixa 1 e 2 , chamada de faixa 1,5
} 
de 170 mil unidades para o ano 22 . Por outro lado, a meta de 610 mil unidades habitacionais também não foi cumprida, sendo entregues tão somente 434.405 moradias (SILVA e NASCIMENTO, 2019).

O futuro do PMCMV com o governo Bolsonaro não parece ter uma melhor sorte, isto porque o Ministério das Cidades foi fundido com o da Integração Nacional, virando o Ministério do Desenvolvimento Regional, com isso a política pública em questão perde em mobilização e em expertise. Ademais, o governo convive diariamente com cortes orçamentários que afetam profundamente a execução de uma política pública como a do Minha Casa Minha Vida.

Saindo da execução e indo para o conteúdo da política pública, o programa habitacional foi concebido como uma estratégia anticíclica de criação de emprego e aquecimento do setor produtivo da construção civil. Rolnik (2015, p. 290-291) narra a concepção do programa:

\begin{abstract}
Nesse momento os empresários atingidos, liderados pela Gafisa e apoiados pela CBIC, passam a intensificar o lobby junto a Fazenda para implementar um "pacote habitacional" nos moldes do programa mexicano, que por sua vez havia sido inspirado no modelo chileno (...) o pacote foi elaborado pelo governo em diálogo direto com os empresários e investidores envolvidos, inicialmente, tinha como objetivo salvar as empresas em débâcle e, ao mesmo tempo, funcionar como medida contra cíclica para garantir empregos e crescimento num cenário internacional desfavorável. Nesse sentido, suas ações deveriam ser imediatas e, portanto, desviar de qualquer política complexa que exigisse longo tempo de maturação ou que encontrasse resistências, como é o caso de uma política fundiária.
\end{abstract}

Assim, o programa optou por uma concepção de provisão de moradia voltada apenas ao número de moradias produzidas sem uma preocupação consistente com a condição urbana da habitação. 0 referido Programa Habitacional foi incluído inclusive como uma das ações do Programa de Aceleração do Crescimento PAC, ficando ainda mais identificado como uma estratégia de auxílio ao setor de construção civil com grande repercussão no setor e consequente incremento das relações negociais, resultando em aumento de oferta e de preços dos imóveis (PENALVA e DUARTE, 2010). Em função dessa relação próxima com o setor produtivo, a solução da moradia foca unicamente em um pilar, qual seja, a produção de unidades prontas, não havendo qualquer diversificação nas estratégias. Repete, portanto, o mesmo erro da política proposta pelo BNH e dissemina o sonho da casa própria como única solução possível para provimento habitacional23.

Continua-se a abordar o acesso à moradia, um direito fundamental previsto na legislação constitucional e internacional, como algo ligado umbilicalmente à geração de empregos e fortalecimento da cadeia produtiva da construção (PENALVA e DUARTE, 2010). Veja-se, por exemplo, que este objetivo era oficialmente

\footnotetext{
22 Disponível em: <https://economia.estadao.com.br/noticias/geral,governo-cumpre-so-13-5-da-meta-do-minha-casa-para-maispobres,70002149698 >.

${ }^{23}$ A crença na propriedade privada como única capaz de prover segurança às pessoas foi inclusive assinalada pela presidenta Dilma Roussef: Investir em moradia digna para a população é investir na proteção e na segurança das famílias. A casa própria contribui para que as famílias tenham uma vida melhor, para que as crianças e os jovens se sintam protegidos, para que os laços familiares e as amizades se desenvolvam, para que as famílias construam um lar. A frase foi dita no programa Café com a Presidenta, conforme matéria da EBC - Empresa Brasileira de Comunicação. Disponível em: <http://www.ebc.com.br/2012/08/minha-casa-minha-vidatem-1-milhao-de-moradias-construidas-diz-presidenta>. Acesso em 11 de julho de 2019
} 
encampado pelo Ministério da Cidade que em sua Cartilha demonstrativa do Programa habitacional estatuiu que os principais objetivos do PMCMV eram: Implementação do Plano Nacional de Habitação, construção de um milhão de moradias, aumento do acesso das famílias de baixa renda à casa p própria; geração de emprego e renda por meio do aumento do investimento na construção civil ${ }^{24}$.

Conclui-se que as críticas centrais direcionadas ao MCMV podem ser aglutinadas em dois eixos: implementação sem uma coordenação com a política urbana e com a utilização de instrumentos urbanísticos e o tratamento monolítico das carências habitacionais apenas pela via da casa própria. Assim, nas próximas seções serão analisados estes dois aspectos importantíssimos para o bom funcionamento de uma política habitacional

\section{A questão urbana e fundiária como ponto central}

O maior entrave para o acesso da população à moradia adequada é, basicamente, a incompatibilidade entre o valor da moradia (aluguel, compra etc.) e a capacidade financeira das famílias de baixa renda. O custo de uma moradia digna é muito alto nas cidades brasileiras. Segundo a Pesquisa de Orçamentos Familiares (POF) 2017-2018 do IBGE, que analisou a composição dos gastos e do consumo das famílias segundo as classes de rendimento, entre julho de 2017 e julho de 2018, o grupo de despesas que mais pesa no bolso da família brasileira é habitação, abocanhando $36,6 \%$ da renda das famílias (IBGE, 2019). Nestes termos, a habitação é a necessidade básica mais onerosa para a vida das famílias nas cidades. O custo do aluguel e do preço de compra dos imóveis está vinculado diretamente ao valor da terra, que é formado a partir de um mercado especulativo baseado na escassez (PLANHAB, 2009).

O preço da terra é um fator que dificulta o provimento de moradia de interesse social bem localizada, ou seja, com o alto valor dos terrenos, torna-se difícil a localização de projetos habitacionais em locais de boa infraestrutura, com serviços urbanos essenciais e oferta de trabalho. A população de baixa renda tem sido forçada a morar cada vez mais longe dos centros urbanos, uma vez que ali estão as opções mais baratas. Moram cada vez mais longe dos lugares com boas ofertas de emprego e infraestrutura urbana.

Ao longo dos anos e com as diversas políticas habitacionais adotadas, ocorreu uma periferização da moradia social, com uma expansão horizontal da cidade e ampliação de suas fronteiras para as áreas rurais. Por outro lado, nota-se o esvaziamento dos grandes centros que contam com diversos vazios urbanos e imóveis vagos.

\footnotetext{
${ }^{24}$ Cartilha do Ministério da Cidade sobre o Programa Minha Casa Minha Vida. Disponível em: < http://www.pbqph.com.br/arquivos/download/Cartilha Mcmv.pdf >
} 
Mariana Fix (2011), ao analisar o PMCMV, descreve o resultado dessa política habitacional para a vida das pessoas e das cidades ${ }^{25}$, é interessante observar que os argumentos também podem ser utilizados para criticar a política do BNH:

\begin{abstract}
O modelo favorece, no caso da provisão de 0 a 3 salários, principalmente a produção de casas térreas em grandes conjuntos nas periferias urbanas ou em áreas rurais que serão transformadas em urbanas. A operação depende da mudança nos limites do perímetro urbano autorizada pelas Câmaras Municipais que, frequentemente, representam os interesses dos proprietários de terra. Apenas essa mudança da venda da terra de hectares (área rural) para metros quadrados (área urbana) é mecanismo poderoso de apropriação de renda. O espraiamento resultante desse modelo tem alto custo para o poder público, uma vez que a rede de infraestrutura (sistema viário, água, saneamento, energia, etc.), transportes e serviços (escola, cultura, lazer, etc.) terá que ser estendida. O pacote foi inicialmente lançado sem estimulo à ocupação de imóveis construídos vagos, apesar dos inúmeros edifícios vazios existentes nos centros urbanos e das políticas urbanas já elaboradas para favorecer seu uso. Prevalece, assim, a lógica de produção que interessa ao setor da construção (FIX, 2011, p. 143).
\end{abstract}

Por outro lado, ao impor às políticas habitacionais uma dinâmica baseada apenas na compra de propriedade privada, há uma injeção de recursos no mercado imobiliário, esse aporte de recurso infla e aquece o próprio mercado e aumenta os preços dos imóveis, beneficiando os investidores e os proprietários. Assim, os recursos públicos injetados acabam por dificultar ainda mais o acesso da população mais pobre à moradia.

Uma política habitacional só será eficaz se vier acompanhada de uma política fundiário-urbanística que enfrente a questão do preço da terra. Somente os programas habitacionais acompanhados pela implementação de instrumentos de democratização do acesso a terra podem realmente efetivar o acesso à moradia adequada a toda população brasileira.

O Estatuto da Cidade e a Constituição Brasileira de 1988 têm por escopo justamente o enfrentamento dessa dinâmica de segregação social que ocorreu no Brasil. Nesse sentido, trazem em seu bojo diversos instrumentos urbanísticos que, se geridos de forma democrática, podem regular o mercado e o preço da terra visando baratear os custos de moradia e produzir terra urbanizada para moradia com valor acessível e bem localizada.

Veja-se, por exemplo, que a ociosidade dos imóveis centrais pode ser combatida com a implementação de instrumentos de efetivação da função social da propriedade urbana como o parcelamento ou edificação compulsórios e o IPTU progressivo no tempo. Nesse caso, a qualidade do espaço urbano pode ser potencializada com o movimento que os moradores dos programas trariam para o comércio, serviço e dia a dia dos entornos.

\footnotetext{
25 No mesmo sentido, dispõem Balbim, Krause e Lima Neto (2015, p. 29), ao analisar o PMCMV: Inúmeros outros prejuízos também são causados ao conjunto de nossas cidades - reforço do processo de periferização, acirramento do mercado imobiliário e imposição da necessidade de realização de mais e mais viagens cotidianas para ligar o local do emprego, do estudo etc. ao distante local de moradia -, sem contar que se perdem oportunidades de inovação que poderiam estar sendo gestadas em formas alternativas de acesso à moradia.
} 
Quanto à especulação imobiliária, essa pode ser combatida com uma política tributária adequada. Todos esses dois instrumentos poderiam aumentar a oferta e reduzir o preço dos imóveis centrais, viabilizando a aquisição por agentes públicos, privados e comunitários.

Entretanto, não basta apenas uma articulação da política habitacional com a política urbana, é necessário também uma diversificação dos produtos habitacionais ofertados para um melhor enfrentamento das carências habitacionais. A próxima seção cuida de dissecar esse assunto.

\section{Diversificação da política habitacional}

A casa própria como forma de provisão de moradia nem sempre foi preponderante sobre o aluguel no Brasil. A difusão da ideia de que a aquisição da propriedade privada seria o meio mais adequado para o provimento habitacional foi favorecida por diversos fatores, tais quais: uma política habitacional concebida com um viés marcadamente econômico, histórico inflacionário brasileiro e instabilidade política dos últimos 50 anos.

De uma leitura atenta do histórico de nossas políticas habitacionais, chega-se à conclusão de que a elaboração e a implementação dessas políticas, nos últimos anos e décadas, foram exclusivamente voltadas à concessão da casa própria. O nome do atual programa habitacional, qual seja Minha Casa, Minha Vida, tem um forte simbolismo e representa o quanto a ideia de casa própria teria importância na vida cotidiana das pessoas. Entretanto, a casa própria não é a única forma de acesso e nem mesmo a forma mais ideal de acesso à moradia. Ademais, deve-se salientar que a universalização do direito à moradia digna não pode ser concretizada apenas com uma forma única de provisão habitacional.

A moradia digna não é implementada apenas com mecanismos de acesso à financiamentos e à casa própria, mas também por uma diversificação de medidas de provisão habitacional. A casa própria pode ser uma boa opção para uma parte da população, entretanto a universalização do acesso à moradia demanda uma gama variada de soluções, tais quais: subsídio direto às famílias pobres, implementação de parque público de moradias, promoção pública de locação social de unidades habitacionais, urbanização, regularização e integração de assentamentos precários etc.

Assim, um dos elementos mais importantes de uma política de provisão habitacional é a sua diversidade. Os problemas de falta de moradia digna são diversificados e, portanto, demandam ações formuladas para cada caso específico. Poderia o Estado oferecer uma política habitacional semelhante para a população em situação de rua e para assalariados com carteira assinada que ganham dois salários mínimos? Ou então, pode-se oferecer uma política habitacional semelhante a uma favela consolidada e aos cortiços? Os idosos devem ter o mesmo tratamento de provisão habitacional que os estudantes? 
A resposta a essas perguntas caminha para a conclusão de que situações diferentes requerem soluções e atuações distintas do poder público. Por este motivo, a política habitacional necessita apresentar uma multiplicidade de opções de atuação, mirando solucionar a precariedade habitacional em todas as suas formas. Deve ser estruturada, portanto, por programas e estratégias diversificados e adequados para o enfrentamento dos distintos problemas e necessidades habitacionais.

Nesse sentido, Cruz e Morais (2009, p. 42) aduzem²6:

(...) os gestores de políticas públicas não devem se concentrar exclusivamente na "casa própria" como a melhor solução de habitação. Uma gama mais ampla de opções de habitação com diferentes modalidades, preços, qualidades e locais devem estar disponíveis para as famílias brasileiras, que assim poderiam escolher as soluções que se encaixem em suas necessidades habitacionais. Nesse sentido, a locação pode oferecer uma boa solução para jovens em busca de oportunidades de emprego e migrantes recém-chegados. Por outro lado, o mercado de aluguel pode ser manejado como um instrumento importante para combater a escassez de habitação em aglomerações urbanas e em áreas urbanas em franco crescimento. Além disso, os gestores devem dar mais atenção a diversas variáveis como a distribuição de renda, a composição familiar e as variáveis do ciclo de vida ao delinear políticas e programas de habitação, se quiserem promover a inclusão econômica e social no mercado imobiliário brasileiro.

Da mesma forma, Raquel Rolnik e Jeroen Klink (2011, p. 109) criticam as políticas públicas brasileiras que invariavelmente olvidam as especificidades próprias de cada região:

\begin{abstract}
Além da concentração da precariedade em certos territórios e das disparidades reveladas por alguns indicadores específicos, os indicadores apresentados aqui expõem a necessidade de políticas desenhadas especificamente para certos territórios. No entanto, as políticas brasileiras de provisão de condições de urbanização e de desenvolvimento econômico apresentam padrões uniformes de intervenções, dialogando pouco com as especificidades regionais, como por exemplo, da Amazônia, com sua ocupação pouco adensada e seu meio ambiente peculiar. Desde o BNH assistimos ao desenvolvimento de uma política sob um único molde, realidade que não se modificou muito, apesar da introdução de novos programas no setor da habitação.
\end{abstract}

Portanto, em razão da diversidade das carências habitacionais, alternativas ao direito de propriedade devem ser compreendidas pelo Estado na formulação de suas políticas de moradia, tais quais: o aluguel, a concessão de direito real de uso, a legitimação da posse etc.

\title{
CONSIDERAÇÕES FINAIS
}

Assim, o direito à moradia não deve ser interpretado em um sentido estreito ou restrito que o equipara com, por exemplo, o abrigo provido meramente de um teto sobre a cabeça dos indivíduos. Precisa ser visto

\footnotetext{
${ }^{26}$ Tradução livre do trecho: (...) policy makers should not focus exclusively on owner-occupied housing as the best housing solution, but that a wider range of housing options with different modalities, prices, qualities and locations should be available to Brazilian households, from which they can choose the solutions that fits better their housing needs. In this sense, rental housing can offer good housing solutions for young people in search of employment opportunities and newly arrived migrants, with the importance of rental markets to alleviate housing shortage increasing in urban agglomerations and fast growing urban areas. Furthermore, policy makers should give more attention to variables such as wealth and income distribution, household composition and life cycle variables when desiging housing policies and programmes, if they want to promote economic efficient and social inclusion in the Brazilian housing markets."
} 
como um direito a viver com segurança paz, dignidade e infraestrutura urbana. A moradia, portanto, deve vir acompanhada de uma infraestrutura urbana que tenha disponibilidade de serviços, materiais, facilidades e infraestrutura essenciais para saúde, segurança, conforto e nutrição, além de acesso sustentável a recursos naturais e comuns, água apropriada para beber, energia para cozinhar, aquecimento e iluminação, facilidades sanitárias, meios de armazenagem de comida, depósito dos resíduos e de lixo, drenagem do ambiente e serviços de emergência.

Para a concretização desta questão, as políticas habitacionais devem ser coordenadas com a política urbana da cidade. Não se pode, portanto, pensar a moradia somente relacionada a uma unidade habitacional, mas sim vinculada a seu entorno e ao planejamento urbano. Por isso, entende-se que o direito à moradia está contido no conceito amplo de direito à cidade. Assim, uma política habitacional só será eficaz se vier acompanhada de uma política fundiário-urbanística que enfrente a questão do preço da terra. Somente os programas habitacionais acompanhados pela implementação de instrumentos de democratização do acesso a terra podem realmente efetivar o acesso à moradia adequada a toda população brasileira.

O Estatuto da Cidade e a Constituição Brasileira de 1988 têm por escopo justamente o enfrentamento desta dinâmica de segregação social que ocorreu no Brasil. Nesse sentido, trazem em seu bojo diversos instrumentos urbanísticos que, se geridos de forma democrática, podem regular o mercado e o preço da terra visando baratear os custos de moradia e produzir terra urbanizada para moradia com valor acessível e bem localizada. Por exemplo, a ociosidade dos imóveis centrais pode ser combatida com a implementação de instrumentos de efetivação da função social da propriedade urbana como o parcelamento ou edificação compulsórios e o IPTU progressivo no tempo.

Por outro lado, nos processos de formulação das políticas públicas, o poder público deve estar atento aos diversos tipos de necessidades e deve formular diferentes tipos de solução para a adequação das diversas carências. Assim, as políticas públicas de habitação não devem focar exclusivamente na propriedade privada como única solução possível para a questão da moradia e devem estar atentas a formas alternativas de provimento deste direito que congreguem diferentes modalidades, preços, qualidades e localizações que se encaixem no perfil social e econômico de cada pessoa ou família.

O PMCMV foi a política hegemônica durante a segunda década do século XXI e não veio efetivado com uma política urbana que democratize o acesso à terra, contribuindo, portanto, para uma maior desigualdade sócio espacial. Por outro lado, a concentração da política habitacional apenas no acesso à moradia pela propriedade privada acabou por dificultar o acesso das pessoas à uma moradia digna. 


\section{REFERÊNCIAS}

AINA, E. M. B. O direito à moradia nas relações privadas. Rio de Janeiro: Lumen Juris, 2009. 217p.

BARCELLOS, A. P.. A eficácia jurídica dos princípios constitucionais: 0 princípio da dignidade da Pessoa Humana. Rio de Janeiro: Renovar, 2002. 335p.

BONDUKI, N. Do projeto moradia ao programa minha casa minha vida. Teoria e Debate, v. 82, p. 8-14, 2009.

BONDUKI, N. Origens da habitação social no Brasil: arquitetura moderna, lei do inquilinato e difusão da casa própria. 6. ed. São Paulo: Estação Liberdade, 2011. 343p.

BONDUKI, N. Pioneiros da Habitação Social: Cem anos de política pública no Brasil. São Paulo: UNESP, 2014. 387p.

BONDUKI, N. Avanços, limitações e desafios da política habitacional do governo Lula - direito à habitação em oposição ao direito à cidade. In: FERNANDES, E; ALFONSIN, B. (Org.). Direito à moradia adequada: o que é, para quem serve, como defender e efetivar. Belo Horizonte: Fórum, 2014.

CANOTILHO, J. J. G. Direito Constitucional. 7. ed. Coimbra: Almedina, 2010. 1522p

CANOTILHO, J. J. G; MOREIRA, V. Constituição da República portuguesa anotada, artigos 1 a 107‥ Coimbra: Coimbra Editora, 2007. $1152 \mathrm{p}$.

CARLI, A. A. Bem de família do fiador e o direito humano fundamental à moradia. Rio de Janeiro: Lumen Juris, 2009.181 p.

CARDOSO, A. L. Desigualdades urbanas e políticas habitacionais. Rio de Janeiro: Ippur, 2001

CARVALHO, Ana Karoline; NASCIMENTO, Manuela Maria Pereira. O HABITAR NO ESPAÇO GEOGRÁFICO: UMA BREVE DISCUSSÃO SOBRE O PERCURSO HISTÓRICO DAS POLÍTICAS HABITACIONAIS BRASILEIRAS.

DAVIS, M. Planeta favela; tradução de Beatriz Medina. São Paulo: Boitempo Editorial, 2006. 272p.

DIMOULIS, D.; MARTINS, L. Teoria Geral dos Direitos Fundamentais. 5. ed.. São Paulo: Editora Atlas, 2014. 331p.

FARIA, J. E. Direitos Humanos, Direitos Sociais e Justiça. São Paulo: Malheiros, 2002. 155p.

FERNANDES, E. A nova ordem jurídico-urbanística no Brasil. In: FERNANDES, E.; ALFONSIN, B. Direito urbanístico: estudos brasileiros e internacionais. Belo Horizonte: Del Rey, 2006. p. 3-23.

FERNANDES, E. Juízes: despreparados ou ideológicos? Artigo de opinião. Texto disponível em:

<http://terrorismobranco.wordpress.com/2012/02/10/juizes-despreparados-ou-ideologicos/>. Acesso em: 02 fev. 2012

FIX, M. A. B. Financeirização e transformações recentes no circuito imobiliário no Brasil. 2011. 263 f. Tese (Doutorado em Desenvolvimento Econômico) - Instituto de Economia, Unicamp, Campinas, 2011.

FRANZONI, J.; LUFT, R. M. Onde mora o direito à moradia? In: CLÉVE, C. M. Direito Constitucional Brasileiro: Teoria da Constituição e Direitos Fundamentais. São Paulo: Thomson Reuters Revista dos Tribunais, 2014. p. 967-988.

FUNDAÇÃO JOÃO PINHEIRO. Centro de Estatística e Informações. Déficit habitacional no Brasil 2013-2014. 2016. Disponível em: < http://www.fjp.mg.gov.br/index.php/docman/cei/informativos-cei-eventuais/634-deficit-habitacional-06-09-2016/file>. Acesso em: 13 jul. 2017.

HARVEY, D. A justiça social e a cidade. São Paulo: Hucitec, 1980. 291p.

HARVEY, D. O trabalho, o capital e o conflito de classes em torno do ambiente construído nas sociedades capitalistas avançadas. Espaço e debates, n. 6, v. 2, 1982. p. 6-35.

IBGE. Pesquisa de orçamentos familiares 2017-2018 : primeiros resultados / IBGE, Coordenação de Trabalho e Rendimento. - Rio de Janeiro: IBGE, 2019. $69 \mathrm{p}$

IBGE. Censo demográfico 2010. Rio de Janeiro, 2012.

IBGE. Pesquisa Nacional por Amostra de Domicílios. Rio de Janeiro, 2015.

KRAUSE, C; BALBIM, R; LIMA NETO, V. Minha Casa Minha Vida, nosso crescimento: Texto para Discussão no 1853. Rio de Janeiro: IPEA, 2013.

MARICATO, E. A terra é um nó na sociedade brasileira... também nas cidades. Petrópolis: Cultura Vozes, p. 7-22, 1999.

MARICATO, E. A Nova Política Nacional De Habitação. Jornal O Valor, São Paulo, 24 nov. 2005.

MARICATO, E. É preciso repensar o modelo. Arquitetura e Urbanismo, São Paulo Setembro/2009, Ed. 186. 2009, p.63.

MINISTÉRIO DAS CIDADES. PlanHab: Plano Nacional de Habitação - Pacto nacional pela moradia digna (2009 - 2023). Brasília:

Secretaria Nacional de Habitação, Ministério das Cidades, 2009. 
ORGANIZAÇÕES DAS NAÇÕES UNIDAS - ONU. World Urbanization Prospects HIGHLIGHTS 2014 revision. ONU, 2014. Disponível em: <https://esa.un.org/unpd/wup/publications/files/wup2014-highlights.pdf> Acesso em: 18 ago. 2017.

PENALVA, Angela Moulin S.; DUARTE, Sandro Marino. Política habitacional no Brasil: uma nova abordagem para um velho problema. RFD-Revista da Faculdade de Direito da UERJ, n. 18, 2010.

PISARELLO, G. Vivienda para todos: um derecho em (de) construcion. El derecho a uma vivenda digna adecuada como derecho exigible. Barcelona: Icaria Editorial, 2003. 284p.

ROLNIK, R. Zonas de especial interesse social. Dicas: ideias para ação municipal. São Paulo, PóLIS, n.117, 1998.

ROLNIK, R. É possível uma política urbana contra a exclusão?. Serviço Social e Sociedade, São Paulo, v.XXIII, n.72, p.53-61, 2002.

ROLNIK, R. O que é cidade. São Paulo: Brasilense, 2004.p.87

ROLNIK, R. A construção de uma política fundiária e de planejamento urbano para o país: avanços e desafios. Políticas Sociais Acompanhamento e Análise, no12, fev. 2006, IPEA, pp.199-210.

ROLNIK, R. Guerra dos lugares: a colonização da terra e da moradia na era das finanças. São Paulo: Boitempo, 2015. p. 423.

ROLNIK, R.; NAKANO, K. As armadilhas do pacote habitacional. Le Monde Diplomatique Brasil, seção Moradia, ano 2, n.20 p. 4-5, mar. 2009.

ROLNIK, R.; KLINTOWITZ, D.; REIS, J.; BISCHOF, R. Como produzir moradia bem localizada com recursos do programa minha casa minha vida? Implementando os instrumentos do Estatuto da Cidade. Brasília: Ministério das Cidades, 2010.

ROLNIK, R.; KLINK, J. Crescimento econômico e desenvolvimento urbano: por que nossas cidades continuam tão precárias? Novos estudos-CEBRAP, n. 89, p. 89-109, 2011.

SANTOS, M. São Paulo: metrópole fragmentada corporativa. São Paulo: Nobel, 1990.

SANTOS, M. Técnica, espaço e tempo: globalização e meio técnico científico informacional. 3 ed. São Paulo: HUCITEC, 1997

SANTOS, M. O espaço dividido: os dois circuitos da economia urbana dos países subdesenvolvidos. Trad. de MyrnaT. R. Viana. São Paulo: EDUSP, 2004 [1979]. 433 p.

SANTOS, A. P. Tributação imobiliária no Brasil. Um difícil percurso rumo à política urbana. Finisterra, Lisboa, n. 97, p. 103-118, maio 2014. Disponível em: <http://www.scielo.mec.pt/scielo.php?script=sci_arttext\&pid=S0430-0272014000100006\&lng=pt\&nrm=iso>. Acesso em: 26 ago. 2017.

SANTOS, A. P.; LUFT, R. M.; MEDEIROS, M. G. P. Direito à moradia: um direito social em construção no Brasil - a experiência do aluguel social no Rio de Janeiro. Planejamento e Políticas Públicas, n. 46, p. 217-242, 2015.

SANTOS JUNIOR, O. A. A Produção Capitalista do Espaço, os Conflitos Urbanos e o Direito à Cidade. In: SANTOS JUNIOR, O. A. (Org.). Políticas Públicas e Direito à Cidade: programa interdisciplinar de formação de agentes sociais e conselheiros municipais. Rio de Janeiro: Letra Capital; Observatório das Metrópoles; IPPUR/UFRJ, 2011. p. 67-74.

SARLET, I. W. A eficácia dos direitos fundamentais. 6.ed. Porto Alegre: Livraria do Advogado, 2006. 493p

SARLET, I. O Direito Fundamental à Moradia na Constituição: Algumas Anotações a Respeito de seu Contexto, Conteúdo e Possível Eficácia. Revista Eletrônica sobre a Reforma do Estado (RERE), Salvador, no. 20, dez., jan., fev., 2009, 2010. Disponível em: <http://www.direitodoestado.com/revista/RERE-20-DEZEMBRO-2009-INGO-SARLET.pdf>. Acesso em: 13 jul. 2017

SCHREIBER, A. Direito à moradia como fundamento para impenhorabilidade do imóvel residencial do devedor solteiro. In: RAMOS, C. L. S. R.; TEPEDINO, G.; BARBOZA, H. H.; GEDIEL, J. A. P.; FACHIN, L. E.; MORAES, M. C. B. (Org.). Diálogos sobre direito civil: Construindo a racionalidade contemporânea. Rio de Janeiro: Renovar: 2002. p. 77-98.

SILVA, V. A. Direitos fundamentais, conteúdo essencial, restrições e eficácia. São Paulo: Malheiros, 2009.

SILVA, José Afonso . Curso de direito constitucional positivo. 32a edição. Malheiros, 2009.

SOUZA, S. I. N. Direito à moradia e de habitação. São Paulo: Revista dos Tribunais, 2004. 366p.

STRAPAZZON, C. L.; TRAMONTINA, R.. Direitos fundamentais sociais em cortes constitucionais: o caso grootboom - tradução e comentários - social rights in onstitution I ourts: grootboom's s - translation and remarks. Espaço Jurídico: Journal of Law [EJJL], v. 17 , n. 1, p. 285-330, 2016.

TORRES, R. L. A cidadania multidimensional na era dos direitos. In: TORRES, R. L. Teoria dos direitos fundamentais. 2. Ed. Rio de Janeiro: Renovar, 2001. p. 243-342. 